\title{
La propiedad de la tierra como un "haz de derechos". Una contribución desde la campaña bonaerense en un momento transicional (1800-1829)
}

\author{
Cristian Miguel Poczynok \\ Instituto de Historia Argentina y Americana "Dr. Emilio Ravignani", \\ Universidad de Buenos Aires, Argentina \\ cristianpoczynok@gmail.com
}

Cita sugerida: Poczynok, C. M. (2018). La propiedad de la tierra como un "haz de derechos". Una contribución desde la campaña bonaerense en un momento transicional (1800-1829). Mundo Agrario, 19 (41), e083. https://doi.org/10.24215/15155994e083

Recibido: 3 de Octubre 2017 - Aceptado: 17 de Mayo 2018 - Publicado: 15 de Agosto 2018

(c) (1) (5) (2) Esta obra está bajo licencia Creative Commons Atribución-NoComercial-CompartirIgual 4.0 Internacional cc) 


\title{
La propiedad de la tierra como un "haz de derechos". Una contribución desde la campaña bonaerense en un momento transicional (1800-1829)
}

\author{
A contribution about land property as a "bundle of rights" in Buenos Aires countryside during a time of transition \\ $(1800-1829)$
}

\author{
Cristian Miguel Poczynok \\ Instituto de Historia Argentina y Americana "Dr. Emilio Ravignani", \\ Universidad de Buenos Aires, Argentina \\ cristianpoczynok@gmail.com
}

\section{Resumen:}

El derecho de propiedad de la tierra es una construcción histórica que es necesario comprender. Aquí, revistamos la noción a inicios del siglo XIX en la campaña de Buenos Airespara concebir la propiedad como un "haz de derechos" que denote la cultura jurisdiccional, la configuración corporativay la concepción casuística del antiguo régimen. Para ello, indagamos qué significaba ser propietario realizando un relevamiento cuantitativo del fondo judicial del Archivo General de la Nación, y una descripción densa de varios juicios para observar la dinámica propietaria y la cultura jurídica en un contexto de transición.

Palabras ClaVe: Derechos de propiedad, Tierras, Crecimiento económico, Buenos Aires, Siglo XIX.

\section{Abstract:}

Property right over land is a historical construction that should be analyzed. Here, we examine this notion as a "bundle of rights" in Buenos Aires countryside at the beginning of the 19th century, in order to characterize the jurisdictional culture, the public corporation and the casuistic conception of the ancient regime. To that end, this work inquires into the meaning of being a property owner at that time by a quantitative study of the National General Archive judicial files, and by a thick description of several trials, with the objective of analyzing the dynamics regarding property and the judicial culture in a context of transition.

KEYWORDS: Property, Possession, Lands, Economic growth, Buenos Aires.

\section{INTRODUCCIÓN}

A pesar de la vasta bibliografía producida desde diferentes corrientes, la mayoría de los estudios sobre la propiedad de la tierra posee una raigambre teórica relativamente homogénea, vinculada a una concepción restringida de los derechos de propiedad. La propiedad es visualizada como una institución que se deduce de las normativas escritas desde la dogmática jurídica, y se reduce a considerar la propiedad meramente como objeto. A la vez, contempla una relación intrínseca entre crecimiento económico y seguridad jurídica de la propiedad, y contrapone la forma feudal, imperfecta, limitada o precapitalista, a otra liberal, moderna, burguesa, perfecta, absoluta o capitalista (Avellaneda, 1864; Cárcano, 1972; Coni, 1927; Oddone, 1956; Giberti, 1985; Azcuy Ameghino, 2002). En mayor o menor medida contribuyen a la sacralización de una forma de la propiedad, que deviene en la ahistorización de un concepto cargado de ideología (Congost, 2007).

A partir de la renovación historiográfica argentina iniciada a fines de los '60, que se abocó al estudio de contabilidades de estancia y planteó la existencia de un mercado interno colonial impulsado por los "polos de arrastre" (Halperín Dongui, 1969, 1975; Assadourian, 1982; Garavaglia, 1983), varios investigadores ampliaron la base de los propietarios y de las unidades productivas con el uso de nuevas fuentes como diezmos, padrones y censos, y generaron el resquebrajamiento de la imagen polarizada del mundo agrario predominante (Garavaglia, 1987). Sin embargo, aún estaban permeados por una perspectiva de la propiedad restringida a la forma "título", por lo que sólo se considera con derecho a la tierra a aquellos que en los censos son denominados como propietarios. Se considera como "transparente" un documento producido por los vecinos de cada distrito, es decir, sin que se ponga en entredicho por qué unos aparecen como propietarios y otros no -con alguna excepción que intuía otras concepciones de derechos de propiedad (Fradkin, 1995; 
Mayo, 2004)- Además, impulsaron una diferenciación analítica entre el acceso a la tierra y la apropiación privada/jurídica, y entre las unidades de producción y las “propiedades” rurales (Garavaglia, 1999; Fradkin, 2000).

Estos estudios brindaron la posibilidad de una microrregionalización de las investigaciones que aportaban piezas distritales al mosaico de la campaña bonaerense. San Antonio de Areco, San Nicolás de los Arroyos, Monte, Ranchos, Chascomús, Dolores, Lobos, San Pedro, Azul, entre otros, fueron ejemplo de nuevas historias locales con una perspectiva renovada, en la que pequeños y medianos productores con un acceso a la tierra diverso eran parte de la expansión agropecuaria (Banzato, 2001). En este sentido, uno de ellos marcó con particular énfasis cómo la antigua posesión comenzaba a ser marginada del mundo jurídico de los derechos de propiedad (Banzato, 2000). Otros trabajos avanzaron sobre otras formas de apropiación jurídica de la tierra: la enfiteusis, las donaciones condicionadas y los boletos de premios (Infesta y Valencia, 1987; Infesta, 2003).

Mientras tanto, otros autores continúan fomentando una relación axiomática entre crecimiento económico y seguridad jurídica (North, 1993; Amaral, 1998; Adelman, 1999; Brown, 2001). Observan el cambio en el derecho de propiedad en clave evolucionista y teleológica, que habría permitido el desarrollo económico a partir de una mayor eficacia institucional y una reducción de costos de transacción. En cierto modo, entroncan con la historiografía "estatalista". Esta visión supone que el Estado moderno liberal aplica una determinada doctrina jurídica liberal, y defiende una propiedad "perfecta” o más absoluta que otra anterior (Congost, 2007, p. 73).

Sin embargo, en los últimos años, a nivel internacional se produjo una oleada de investigaciones que ha revistado la problemática en el mundo colonial y en la transición al orden moderno (Herzog, 2015; Congost, Gelman, Santos, 2017). Con la reivindicación del encuentro entre la historia social y la historia del derecho (Clavero, 1974; Vilar, 1983; Palacio y Candioti, 2007) se caracterizó a la propiedad en forma relacional e histórica (Thompson, 1995; Grossi, 1992; Bloch, 2002).

En el horizonte argentino, algunos estudios relativos a Buenos Aires comenzaron a interrogarse sobre la voz propiedad a partir de diversas fuentes, como los documentos del Departamento Topográfico, los contratos de arrendamiento, la Contribución Directa, los debates por el Código Rural de 1865 y los expedientes judiciales de tierras (Canedo, 1993; Fradkin, 1999; Gelman, 2005; Barcos, 2013; Ciliberto, 2013). Cultivaron una perspectiva que comprendió al problema en el marco de un orden jurídico diferente o, al menos, en transición.

En este artículo volveremos sobre la cuestión de la propiedad de la tierra en la campaña de Buenos Aires, entre los años de 1800 y 1830, en pos de analizar los discursos y las prácticas de la propiedad para entrever los modos en que se llevaban a cabo al ras del suelo a partir del uso de los expedientes civiles. ${ }^{1}$ Como señalaba Manuel Antonio de Castro, presidente de la Academia Teórico-Práctica de Jurisprudencia y del máximo tribunal de justicia durante dos décadas tras la abolición de la Real Audiencia, los litigios civiles eran aquellos en los que "el uno posee la cosa litigada, el otro intenta adquirirla, ó recuperarla" (Castro, 1821).

Consideramos que existe una alteridad basada en tres elementos -una concepción jurisdiccional, una composición normativa pluralista y una configuración jurisprudencial de la justicia (Tau Anzoátegui 2000; Garriga, 2004) - que resulta necesarios captar. En este sentido, revistaremos la propiedad de la tierra para comprenderla como un haz de derechos (Congost, 2007), abandonando el significante de una propiedad por la frase conceptual "derechos de propiedad". Esto permite concebir a la propiedad en plural -ya que son muchas las acepciones del derecho- y de manera histórica -porque todo nuevo derecho supone un proceso que, a su vez, anula, limita o modifica a otros derechos-. Criticaremos la deificación conceptual de la propiedad para contribuir al estudio de lo que significaba ser propietario en dicho período, e inquirir sobre los argumentos y estrategias que los partícipes ponían en juego en cada conflicto.

El esquema de trabajo contempla primero delinear el marco conceptual historiográfico, yseguidamente, presentar un análisis cuantitativo de los conflictos por la tierra del fondo del Tribunal Civil del Archivo General de la Nación (AGN). A partir de allí, hacer una lectura cualitativa de una serie de juicios, en pos de 
realizar un "test de los propietarios prácticos" (Congost, 2007, pp. 87-93), para comprender lo normativo a partir de la dinámica social.

\section{La voz de derecho en la historia crítica del derecho y la historia social y agraria de la propiedad}

Ampliar la noción de derecho es fundamental para comprender los múltiples órdenes normativos de la cultura jurisdiccional y problematizar la propiedad. Según la Real Academia Española, entre 1726 y 1852 se mantuvo vigente la siguiente definición de derecho: "es el que dicta la naturaleza; es el ordenado por la Divinidad; es el definido por la Iglesia; es el que constituyeron las gentes; es el establecido por el Príncipe 'supremo legislador en sus dominios'; es el que ordena la ciudad o el pueblo para su gobierno privado; es el que introduce la costumbre" (Tau Anzoátegui, 2000, p. 286). Así, el derecho local era el resultado de "normas nacidas al amparo de un orden informal o espontáneo... que atiende el principio de especialidad y como opuesto a un derecho general" (Pugliese, 2005, p. 225), y la costumbre funcionaba como un área de fricción -dotada de carácter jurídico-, entre la práctica y las disposiciones escritas (Fradkin, 1999).

El carácter desigual de la sociedad del antiguo régimen implica entender a la administración de justicia en términos plurales. No existía una justicia sino "varias justicias", ya que eran múltiples las corporaciones, sin existir necesariamente una entidad normativa superior a la otra. Existían los "bandos" reales, la legislación local, los derechos religiosos y la costumbre, la doctrina jurídica, la práctica forense, entre otras. Así, es necesario prestar igual atención a todas ellas -hasta la sanción del Código Civil (1869), la costumbre será subordinada a la normativa escrita-.

Si contemplamos que la costumbre se encontraba con el mismo carácter jerárquico que otras legislaciones, el armazón político e institucional en que se desarrollaba plenamente era aquel de carácter plural, con su extensión limitada al momento de la centralización política (Tau Anzoátegui, 2000). Esta situación es pasible de ser observada en este período de transición, cuando en Buenos Aires se demolía el orden colonial para construir un estado sobre las bases del liberalismo.

Esta galaxia del concepto de derecho, propia de una cultura jurisdiccional que daba sentido interno al antiguo régimen, permite reconsiderar algunos aportes recientes. Desde la historia de las ideas, Reguera observó a la propiedad como una mentalidad social que, durante el siglo XIX, expresaba una configuración de valores en tres pilares que constituyen al orden liberal: el individuo, la propiedad y la libertad. Más allá de los matices, la élite rioplatense mantuvo un ideal de "individualismo agrario propietario", y sacralizó la función de la "propiedad privada liberal" (2009).

En la misma clave, Zeberio estudió el proceso de codificación, y señaló los mecanismos de invención, homogenización y erradicación de los derechos previamente establecidos. La síntesis del Código Civil fue una visión equilibrada "entre viejas y nuevas concepciones a los efectos de evitar una confrontación con prácticas sociales y económicas de larga existencia en el mundo colonial”, es decir, la pervivencia de limitaciones a la sacralización de la propiedad como resultado de formas comunitarias relativas a la familia y a la herencia. De este modo, durante el siglo XIX "la exclusividad del dominio convive con formas ocultas de derechos comunitarios" (2005, p. 53).

Desde la historia agraria y por nombrar sólo algunas autoras entre otros (Canedo, 1993; Banzato, 2000), Barcos estudió los ejidos de la campaña a partir de la Guardia de Luján. Observó una tensión en las concepciones que atravesaban el abigarrado complejo normativo colonial e independiente, que daba lugar a una "dinámica propietaria" que nacía de la compra y venta cotidiana de chacras y quintas, más que de la ley en sentido restringido (2013). Por su parte, Ciliberto se abocó a las antiguas tierras de los jesuitas en la Chacarita y consideró que hacia la segunda mitad del XIX se "funda el derecho de propiedad (abstracto y absoluto) únicamente en las leyes del Estado". Previamente, el arriendo, la costumbre y los litigios judiciales generaron 
derechos, hecho que daba cuenta de un proceso de redefinición de derechos que iban siendo transformados por la acción del Estado (2000, p. 58). En relación con los partidos de Azul y Tapalqué, Lanteri remarcó que al menos hasta 1860 sólo había un 23\% de tierras apropiadas mediante títulos, mientras que las restantes se ubicaban por fuera de la "propiedad privada plena" pero con derechos de propiedad (2011).

En síntesis, estos nuevos enfoques propiciaron una revalorización de las instituciones, del derecho y de la cultura jurídica. De diversas maneras, criticaban la visión de la propiedad que trasladaba el criterio actual al pasado. Así, brindaron historicidad a la deificación de una concepción de la propiedad; entendieron a los derechos de propiedad como una relación que nacía también de las prácticas agrarias, en las que la estructura socioeconómica y política no es mero contexto.

\section{Los litigios civiles y las disputas por los derechos de propiedad}

Los expedientes civiles nos permiten ahondar en la trama social jurídica de los sectores subalternos y de las concepciones del derecho de los administradores de justicia. Su lectura requiere un esfuerzo conceptual para desentrañar el sentido de las voces jurídicas y la representación y la legitimidad que los actores tenían y brindaban tanto del espacio judicial como del resto de las instituciones. También encierran ciertas distorsiones para la comprensión de la dinámica social. Principalmente, tienen el riesgo de magnificar la conflictividad social y negar los consensos, o de incurrir en generalizaciones a partir del casuismo, o de perderse en el camino de la búsqueda de la veracidad de los testimonios judiciales -cuestión que no tiene sentido, porque la falsedad de un testimonio debía aproximarse lo más posible a la credibilidad en el contexto social en que se produce, ya que, de otra manera, perdería sentido (Mayo, Mallo y Barreneche, 1989)-. Entonces, si bien la fuente condiciona la posibilidad de encontrar una homogeneidad en los datos, hicimos un relevamiento cuantitativo de los juicios por la tierra en pos de visualizar el universo global de litigiosidad e interpretar las frecuencias encontradas. Luego, retomamos un enfoque cualitativo para estudiar patrones argumentativos relativos a la fundamentación de los derechos de propiedad o, dicho de forma más precisa, de las relaciones jurídicas entre las personas y las cosas.

El conteo de litigios lo trabajamos rastreando en el catálogo principal del fondo judicial del Tribunal Civil que posee el $\mathrm{AGN}^{2}$ los autos que denotaban una relación temática con la tierra desde 1800 hasta $1830^{3}$. El punto de arranque es por un problema metodológico: el fondo inicia allí. El de corte encuentra diversas motivaciones, parcialmente subjetivas. La principal es la llegada de Juan Manuel de Rosas al poder y el inicio de un período de estabilización de la campaña.

Los conflictos fueron ordenados en ocho categorías que surgen de los autos de los procesos civiles: 1) tierras o terrenos ${ }^{4}$; 2) reconocimiento o anulación de títulos o escrituras; 3) establecimientos rurales, como fincas, chacras, quintas, etc. -resulta problemática hacienda, que no necesariamente refiere a un problema de tierras en sentido estricto sino al ganado y a la riqueza, aunque estos últimos suelen ser caratulados como cobro de pesos-; 4) formas de acceso a la tierra como aparcería, alquileres y arrendamientos; 5) límites de la propiedad, a saber, deslinde, mensura y mojones; 6 y 7) aquellos que se definen en torno a la propiedad y la posesión; y 8 ) los desalojos. Los datos obtenidos se encuentran en el gráfico 1. 


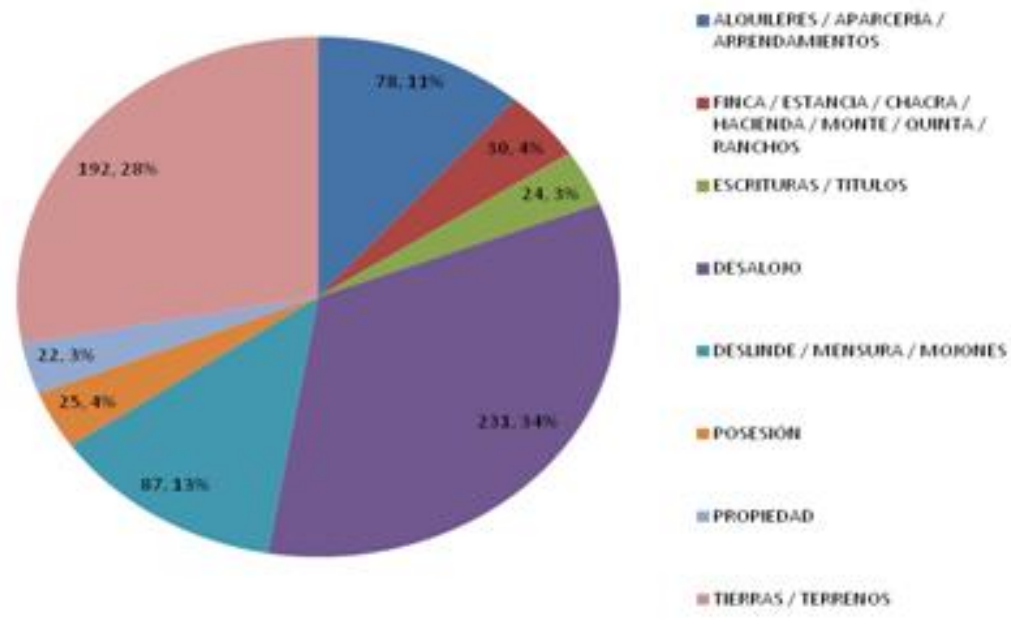

Gráfico 1. Expedientes civiles relativos a los derechos de propiedad de la tierra Fuente: Archivo General de la Nación, Tribunal Civil. ropiedad de la tierra

Encontramos 689 conflictos sobre derechos de propiedad, muchos de los cuales podrían girar en torno a propiedades urbanas (cuartos, habitaciones, casas). A pesar de ello, hay categorías asociadas por antonomasia al ámbito rural, como arrendamientos, aparceria, chacras, quintas, fincas, ranchos, estancia, hacienda, monte, deslinde, mojones, mensura, terrenos y tierras. Así, unos 350 refieren a la campaña, mientras que aquellos eminentemente urbanos son los alquileres (37). El resto de los 302 litigios pueden ser de una u otra esfera. Sin embargo, según Fradkin y Robles (2002), se constatan 96 expedientes por desalojo que refieren al ámbito rural entre 1810 y 1829 . Así, nos quedan unas 206 causas sin poder chequear, como muestra la tabla siguiente:

Tabla 1. Expedientes clasificados por zonas: urbano, rural y variables

\begin{tabular}{|c|c|c|c|}
\hline & URBAYO & RURAL & VARLARLES \\
\hline $\begin{array}{l}\text { ALQTILERES } \\
\text { APARCERIA } \\
\text { ARRENDAMIIENTOS }\end{array}$ & 37 & $\begin{array}{l}1 \\
40\end{array}$ & \\
\hline $\begin{array}{l}\text { CHACRA } \\
\text { ESTANCIA } \\
\text { FINCA } \\
\text { HACIENDA } \\
\text { MONTE } \\
\text { QLINTA } \\
\text { RANCHOS }\end{array}$ & & $\begin{array}{l}3 \\
8 \\
8 \\
4 \\
1 \\
3 \\
3\end{array}$ & \\
\hline $\begin{array}{l}\text { ESCRITURAS } \\
\text { TITULOS }\end{array}$ & & & $\begin{array}{l}20 \\
4\end{array}$ \\
\hline DESALONO & & 96 & 135 \\
\hline $\begin{array}{l}\text { DESLINDE } \\
\text { MENSTRA } \\
\text { MOJONES }\end{array}$ & & $\begin{array}{l}25 \\
61 \\
1 \\
\end{array}$ & \\
\hline POSESIÓX & & & 25 \\
\hline PROPIEDAD & & & 22 \\
\hline $\begin{array}{l}\text { TERRENOS } \\
\text { TIERRAS }\end{array}$ & & $\begin{array}{l}151 \\
41 \\
\end{array}$ & \\
\hline TOTALES & 37 & 446 & 206 \\
\hline
\end{tabular}

Fuente Archivo General de la Nación, Tribunal Civil

Dicho esto, los agrupamos según tres intervalos para observar las frecuencias (tabla y gráfico 2). Allí, encontramos que en primer lugar se destaca que en 1800 -1809 hay unos 172 litigios, en 1810 -1819 se reducen a unos 138, y en $1820-1829$ crece a 379. Así, tras el declive del 20\%, la década del 20 al 29 presenta un incremento notable de la conflictividad en varias categorías: casi más de la mitad si lo comparamos al 
1800 -1809. La tendencia más marcada es en los autos relativos a desalojos, terrenos y mensuras, seguidos por tierras, alquileres y arrendamientos.

Tabla 2. Frecuencia de los expedientes judiciales clasificados

\begin{tabular}{|c|c|c|c|c|c|c|}
\hline & & $1800-1809$ & $1810-1819$ & $1820-1829$ & TOTAL. & \\
\hline 1 & ALQUILERES & 7 & 9 & 21 & 37 & \\
\hline 1 & APARCERIA & & 1 & & 1 & \\
\hline 1 & ARRE NDAMEITIOS & 11 & 8 & 21 & 40 & 78 \\
\hline 2 & CHACRA & & & 3 & 3 & \\
\hline 2 & ESTANCL & 2 & 1 & 5 & 8 & \\
\hline 2 & FINCA & 2 & 3 & 3 & 8 & \\
\hline 2 & HACIENDA & & 2 & 2 & 4 & \\
\hline 2 & MONTE & 1 & & & 1 & \\
\hline 2 & QtINTA & 1 & & 2 & 3 & \\
\hline 2 & RAVCHOS & & & 3 & 3 & 30 \\
\hline 3 & ESCRITURAS & 2 & 5 & 13 & 20 & \\
\hline 3 & rrTULOS & 4 & & & 4 & 24 \\
\hline 4 & DESALOSO & 38 & 48 & 125 & 231 & 231 \\
\hline 5 & DESL.NVE & 6 & 9 & 10 & 25 & \\
\hline$s$ & MENSTRA & 15 & 7 & 39 & 61 & \\
\hline 5 & MOJONES & 1 & & & 1 & 87 \\
\hline 6 & POSESIÓX & 10 & 4 & 11 & 25 & 25 \\
\hline 7 & PROPIFDAD & 2 & 5 & 15 & 22 & 22 \\
\hline 8 & TERRENOS & 36 & 26 & 89 & $15 !$ & \\
\hline \multirow[t]{2}{*}{8} & TIERRAS & 14 & 10 & 17 & 41 & 192 \\
\hline & & 172 & 138 & 379 & 689 & \\
\hline
\end{tabular}

Fuente: Archivo General de la Nación, Tribunal Civil.

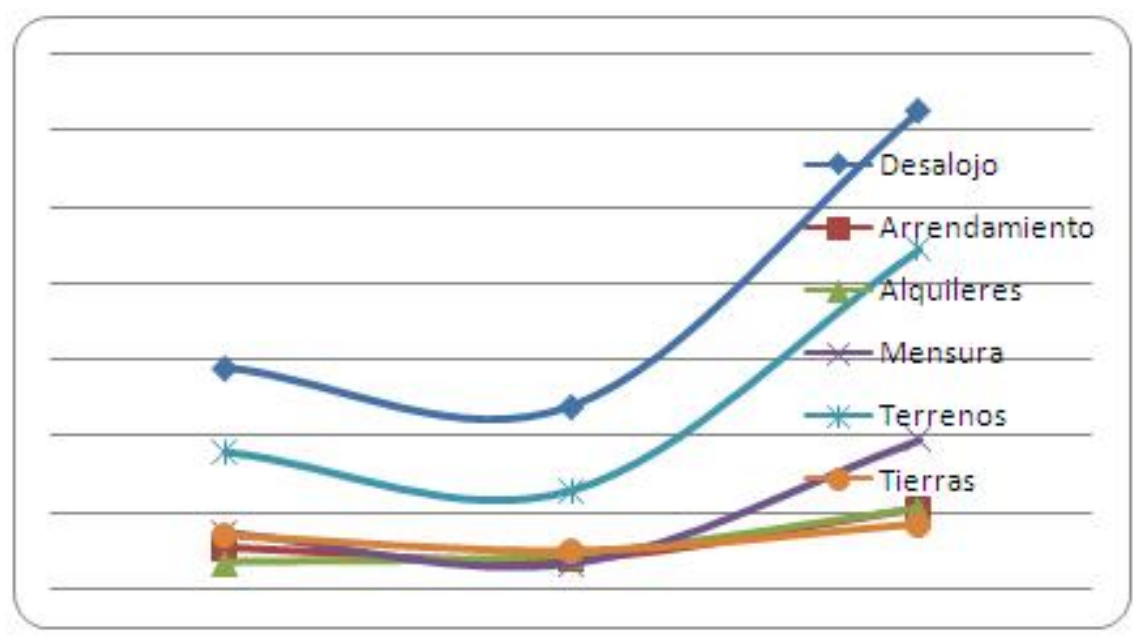

Gráfico 2. Frecuencia de los litigios

Fuente: Archivo General de la Nación, Tribunal Civil.

¿Cómo podemos leer esta tendencia de la litigiosidad? En rasgos generales, podemos mencionar una serie de variables interrelacionadas que presionan sobre los derechos de propiedad de la tierra, entre las que se encuentran, principalmente, los movimientos demográficos y las migraciones internas.

La población rural en Buenos Aires tuvo un crecimiento muy acelerado entre 1744 y 1836: poco más de 6.000 personas en 1744 , en 1778 el doble; en 1815 desplegaba más de 41.000 individuos censados, y en 1836 alcanza las 91.000 personas. Por su parte, la ciudad presenta rasgos similares: 12.044 habitantes en 1740-1750, 45.000 en 1810, y 55.416 hacia 1820 (Garavaglia, 1999). De modo que en un lapso muy reducido crece exponencialmente el mundo rural y se invierte la relación poblacional entre la ciudad y la campaña. Este ritmo no puede ser explicado tan sólo por el crecimiento natural, en especial en la campaña. La afluencia poblacional de las migraciones internas mostraba que Buenos Aires crecía a expensas de otros espacios regionales como el Tucumán y Cuyo (Mateo y Moreno, 1997). Asimismo, esto sugiere la posibilidad de encontrar prácticas propietarias "ajenas" al espacio bonaerense, como puede ser el "descubrimiento" de la minga en las relaciones laborales de la campaña (Garavaglia, 1999). Además, si el avance fronterizo se 
produjo de forma tardía a la crecida poblacional, la utilización y la presión sobre las tierras de antigua colonización cobraron mayor intensidad por el aumento en la densidad poblacional (Barral, Fradkin, Luna, Peicoff, Robles, 2007).

Este punto tiene relación con el debate sobre la "oferta ilimitada de tierras". Mientras algunos negaban lo "ilimitado", otros postulaban una frontera abierta a la colonización que funcionaba como válvula de presión de la conflictividad. Sin embargo, si bien idealmente la posibilidad de avanzar sobre la frontera era válida, las tierras de fronteras tenían otras particularidades. Los precios de los arriendos, por ejemplo, variaban con relación a las distancias entre las unidades productivas y el mercado y, efectivamente, existía una posibilidad real de robos y ataques indígenas (Birocco, 1992; Fradkin, 1997). Por ello, no es casual que éste haya sido el argumento que más utilizaban los denunciantes de tierras para justificar una moderada composición. Se apelaba a la representación simbólica que el espacio colonial tenía sobre las tierras no colonizadas, y la apropiación tras la denuncia y mensura de tierras implicaba convertir el "monte realengo" en "espacio colonial... legible y susceptible de mercantilizar” (Muñoz Arbeláez, 2011, p. 213). En consecuencia, no podemos pasar por alto la concepción que el imaginario social del período tenía sobre esas mismas tierras.

En segunda instancia, tenemos que valorar la redirección de la economía del Río de la Plata ante la crisis del orden colonial. La elite pasó de estar sustentada principalmente por la exportación de metales preciosos del Alto Perú a basarse en la exportación de bienes agropecuarios (Rosal y Schmit, 2004, p. 161). La ganadería bonaerense encontró un contexto excepcional que permitió la existencia de altas tasas de ganancia con un bajo nivel de capital ( Infesta, 2003, pp. 115-120). Así, durante la primera mitad del siglo XIX, los cueros no proporcionaron menos del $60 \%$ de las exportaciones, mientras que el $40 \%$ eran productos derivados de la ganadería: el sebo y el tasajo (Halperin Donghi, 1969, p. 25).

Otra variable fue la intensificación del conflicto entre la producción ganadera y el destrozo de los sembradíos. Dicho conflicto atravesará todo el siglo XIX como ha mostrado Fernanda Barcos respecto delas tierras ejidales (2013). La problemática es de antigua data y se percibe en todas las sociedades preindustriales que aún no poseían un uso eficaz y extensivo de los cercos.

Esto deviene de la valorización del ganado y de la tierra como un factor que presiona sobre el interés por los derechos de propiedad. Los estudios de Garavaglia sobre los precios han demostrado que se mantienen estancados en los inicios de 1800; tienen un lento pero constante ritmo de crecimiento desde la década del 10, y una tendencia más marcada a crecer hacia el 20 (2004, pp. 92-93). Al mismo tiempo, se constatan cambios en la medición de los campos, dado que las mensuras gráficas se usan con más frecuencia desde 1790, y en 1824 se crea la primera autoridad topográfica. Respecto al ganado vacuno, los precios tendieron al alza durante la segunda mitad de la década revolucionaria. El ritmo se incrementó formidablemente hacia 1820 y encontró relación con el movimiento de cabezas de ganado para el abasto anual (Garavaglia, 1999, p. 218 y 2004, p. 118).

Por otro lado, la variabilidad en la circulación de metálico y del papel moneda, sumada a las implicancias económicas y políticas que la Revolución tuvo para la elite comercial -que basaba su predominio en la posición privilegiada de la ciudad como intermediaria de la relación con la metrópoli-, llevó a un proceso de reordenamiento productivo. En consecuencia, parte de sus capitales se volcaron hacia la diversificación de sus inversiones (Halperín Donghi, 2005, p. 114).

Finalmente, un factor político es la revolución y la guerra. Esa situación ayuda a entender el desplome de la estructura estatal y la priorización de los factores político-militares más que las instancias de ordenamiento judicial, al menos durante la década revolucionaria. En este sentido, la evolución cuantitativa de los juicios del fondo civil entre 1800 y 1823 muestra un promedio cercano a la centena anual, pero que a partir de 1823 supera los dos centenares, y desde 1828 hasta tres (Barral, Fradkin, Luna, Peicoff, Robles, 2007, p. 61). Esto significa que, a pesar de las crisis políticas de 1820 o 1827-29, la reforma judicial de 1821 podría ser un punto de inflexión en las posibilidades de acceso a la justicia. Sin embargo, una lectura que pondera la 
relación entre crecimiento demográfico y los procesos por desalojo arroja una visión más pesimista sobre esta cuestión (Gelman, 2016).

\section{Corriendo el velo a los "derechos de propiedad": estrategias judiciales}

\subsection{Los conflictos antes de la década revolucionaria}

El primer caso corresponde a un proceso iniciado en 1800 y finalizado en 1802 . Transcurre en el paraje de San Pedro, partido de Arrecifes, al norte de la campaña bonaerense - una región propicia para cereales como ganadería-, que en 1744 contaba con 435 habitantes y hacia 1812 unas 1.690, es decir, se cuadriplica la población en el mismo espacio (Di Stefano, 1991). Las partes son don Fernando de Alvandea e Ignacio Arce y finaliza con la sentencia de desalojo ${ }^{5}$. El eje del conflicto parecería ser que refiere a lo que una serie de testigos expresaron al presenciar "la recogida del ganado de Arce", que tenía una población "situada en una lonja de tierras que están como realengas sobre la barranca del Río Paraná” a medio cuarto de legua de los terrenos adquiridos por don Fernando.

El demandante obtuvo derechos a los terrenos a través de un boleto de compra y venta. Era una venta resultado de una sucesión, en la que los oferentes eran don Salvador y Adrián Benavides. Este boleto de octubre de 1799, que funcionaría como prueba en el expediente, expresaba que el vendedor "desde hoy en adelante y para siempre me desapodero, desisto y aparto de la acción, propiedad, posesión, título, voz, recurso y de otro cualquier derecho que sobre dichas tierras me pertenezca y pueda pertenecer". Asimismo, se comprometía al "saneamiento de esta venta y tierras (...) para que disponga de ellas a libre voluntad sin dependencia alguna”, para lo cual quedaba a disposición para testificar en caso de pleito judicial, tomando voz y defensa hasta dejarlas "en quieta posesión".

Si bien estas dos fórmulas nota biliares están presentes en los boletos, la alteridad del orden jurisdiccional lleva a indagar los variados derechos que había sobre la tierra. El "haz de derechos" era tan amplio que el desprendimiento se extiende a cualquier otro derecho que relacione al vendedor con la parcela. Asimismo, libera a las tierras de dependencias e insinúa el peso de la palabra del testigo como garantía para la "quieta posesión", como si el "boleto" por sí solo no bastase.

Inmediatamente, una segunda venta de tierras denota una particularidad: se agrega en un boleto ajeno una transacción realizada en otra ocasión y el comprador no se opone. Si bien es conocida la compra y venta informal como práctica habitual, destacamos que se esperó la ocasión para constatarlo por escrito y que puede plantearse un acceso diferencial a formas de validación y obtención de derechos según las condiciones sociales, económicas, etnorraciales y políticas que se poseen.

El conflicto comienza dos meses después del último boleto, cuando Fernando de Alvandea denuncia que en sus tierras se encuentra Ignacio Arce (sin don), y solicita el desalojo y el pago de arrendamientos adeudados. Apela a una exigencia que el Gremio de Hacendados realizaba desde hacía tiempo: para titularse hacendado y mantener ganado en pie se debía tener una suerte de estancia. El alcalde de hermandad, testigo de una de las transacciones, notificó al acusado que "respondió que estaba pronto a mudar su hacienda de dicho terreno pero que para ello necesitaba el plazo de dos meses”. Así, la primera estrategia fue pedir tiempo y aceptar la denuncia.

Posteriormente, el demandante se dirige al alcalde de primer voto y menciona la presencia de más arrendatarios que no le pagan arriendo, a pesar que la demanda habíasido sólo contra una persona. En la nueva notificación que recibió el demandado "dijo que obedecía, pero que también tenía que deducir en el juzgado... [porque] el terreno donde vive está por realengo". La segunda maniobra para alegar su derecho al terreno, entonces, se realiza bajo una fórmula jurídica que "obedece" pero deduce "en el juzgado". Para redoblar el embate, el demandante se revela como capitán de milicias -al inicio se presentaba como un vecino que exigía el desalojo-. Ahora, "suplica y ruega" el desalojo y el arrendamiento en el término de tres días. 
El nuevo escrito no pudo ser entregado por el alcalde de santa hermandad porque Ignacio Arce no estaba en las tierras. Al enterarse de su regreso decide buscarlo por su casa que quedaba a dos leguas y media de distancia, para llevarlo preso y lo asegura con grillos en la casa del alcalde. Esa misma tarde, la esposa Petronila Chaparro, acompañada de don Thomas Taybo -vecino que figuraba en el boleto y cuñado de Salvador Benavides-, presentó una misiva que expresa una tercera estrategia. Firmada por el "Juez Comisionado de la Real Audiencia del Distrito", indicaba que

Ignacio de Arce ha satisfecho al Depositario D. Mateo Cruz los veinte y seis pesos (...) el arrendamiento del terreno que ocupa, correspondiente a la testamentaria del finado D. Juan Tomas Venavides y a los trece años que está establecido en el, al respecto de dos pesos en cada un año.

El fallecido era un "labrador pobre" que vivía en tierras del sargento Alonso Zerrato, heredadas a través de Andrés Ximenez de Fuentes, quien las obtuvo en merced en 1594. Según Di Stefano, Zerrato no tenía ganado y cobraba arriendo a los ocupantes (1991).

Sin embargo, la antigua posesión y la denuncia de violencia serían los últimos alegatos para resistir el desalojo. Reivindica una población treintañal "en unos terrenos realengos, que están linderos con los del finado Don Juan Thomas de Benavidez", y que "propuso a varios vecinos pobres, que estaban poblados en los dichos realengos, haría una presentación de todos para conseguir la propiedad”. Asimismo, denunciaba la relación entre alcaldes y demandantes, al plantear que estaba "coligado con el mismo Alvandea", quien amenazaba con "que le ha de quemar los ranchos haciéndose dueño absoluto". Esta situación habría conseguido que "un hijo suyo [de Ignacio Arce] abandone sus ranchos, montes, y ganados mayores y menores por buscar el Patrocinio y amparo (...) contra el poder del citado Alvandea, que en fuerza de ser hombre rico quiere avasallarlos".

El alegato entroncaba con una cultura jurídica que reconocía a la pacífica ocupación como fuente de derecho. En este sentido, don Pedro Andrés García afirmaba, al referirse a estos labradores que poblaban la campaña, que "la falta de propiedad, aunque una posesión inmemorial se la haya dado, hace que anden errantes, porque se apareció un propietario por una reciente denuncia, que o los desaloja o hace feudales" (Gelman, 1997, p. 150). Sin embargo, también podemos pensar que, ante el fallecimiento de don Juan Thomas Benavidez, a quien podría haber pagado arriendo, Ignacio Arce esté jugando, en alianza con otros productores, sus cartas para hacerse con la propiedad de los terrenos que ocupaba.

Pero la referencia a la violencia no sería sólo de la parte demandada. La sentencia demoraría en ser efectiva. Así, Fernando Alvandea insistía en el desalojo y, tras "haberle reconvenido" a Ignacio Arce, denuncia que "arrancó el cuchillo que a no ser la mediación de otros desde luego se habrían palpado las consecuencias".

En este sentido, no parecen exageradas las expresiones de Esteban Echeverría en El Matadero, cuando narraba una riña por el derecho a las "sobras"

por un lado dos muchachos se adiestraban en el manejo del cuchillo (...) por otro cuatro, ya adolescentes, ventilaban a cuchilladas el derecho a una tripa gorda y un mondongo (...) Simulacro en pequeño (...) del modo bárbaro con que se ventilan en nuestro país (...) los derechos individuales y sociales (1965, pp. 85-86).

Esta afirmación tiene un correlato en la reiterada prohibición de portación de cuchillos y la observancia de los jueces de paz ${ }^{6}$.

Veamos otro conflicto, esta vez en una zona periurbana que trascurre en tierras del convento San Francisco en la Chacarita, donde había hornos de ladrillos y tejas, un obraje textil y una atahona (Fradkin, 1992). Es iniciado en marzo de 1803 por don Manuel Ferreyra, síndico del convento, contra don Manuel García, y exige el desalojo de la quinta arrendada 7 .

Aquí, encontramos cuatro particularidades. Primero, el arrendamiento no se hace por una renta. Las condiciones refieren al mantenimiento de los frutales y de los linderos con un cerco tupido. Segundo, el arrendatario inicia en paralelo otro proceso contra los religiosos por "actitudes temerarias y violentas". Tercero, aparece la figura del defensor de pobres. Finalmente, el síndico apelará a sus fueros religiosos. 
La contrata formal fue expedida en febrero de 1802. Era una quinta "para que disfrutare de su terreno durante el término de tres años con la calidad y condición de que haría renovar el cerco en toda ella poniendo tuna o pita (...), y en que todos los años haría plantar una cuadra de árboles duraznos”. La importancia dada a los frutales radica en el valor que tenían y al proceso de deterioro que tuvo la hacienda tras la expulsión de los jesuitas: hacia 1767 poseía 760 frutales pero en 1779, sólo 150. Además, la condición de plantar "durazneros por año" se habían establecido en las temporalidades a un arrendatario anterior (Fradkin, 1992, pp. 72-74).

El problema surge al finalizar el primer año de contrato. La denuncia indica que

descuidando a todo lo que le era [gravoso] y útil al Convento, extendió sus personales utilidades a más de lo que se le había permitido, y no solo sembró toda la quinta, en donde según noticias ha cogido más de doscientas fanegas en trigo, sino que también recogió la leña (...) que el Convento necesitaba para la quema del material, y vendiéndola sacó a ella muchos pesos.

Ante la notificación, don Manuel García alega que se había presentado con antelación a la denuncia del síndico, ante las presiones que sufría por los religiosos. Advierte que no posee el contrato porque está en otro expediente; solicita que se unan las causas, y apela a la costumbre, consistente en no ser desalojado hasta la cosecha. Por otro lado, destaca que "en la contrata se expresa que el Convento no había de tener más acción ni [derechos] a dicho terreno en el espacio de los tres años". Por ende, "no debería tener otra acción (...) que a compelerme a verificarlas y cumplirlas", esperando que "sea justicia" y evitando "proceder de malicia".

Posteriormente, un "paisano" muestra su apoyo al arrendatario, y luego lo hace el defensor general de pobres "en protección de Manuel García [sin don] pobre desvalido" e “infeliz”. Esta figura judicial solía estar acompañada de asesores letrados. En este caso actuó como defensor don Juan Antonio Zelaya, que estaba suscripto a la Gazeta Mercantil como comerciante y no natural de Buenos Aires (7/6/1810). Este instrumento asumía la representación de las personas "pobres" -en tanto estado-, en pos de una correcta administración de justicia (Rebagliati, 2009).

El defensor señala que la acción del convento sólo habilitaba "a compeler al usufructuario a que verifique y cumpla las condiciones". Remarca el estado deplorable en que estaba la quinta, que forzó a que el arrendatario sólo se abocase a "zampearlos" para que estén a disposición: "cuando entró en ellos se hallaban descubiertos, con camino hasta de carretas y hechos un potrero". Recién tras once meses comenzaba a tener "esperanzas de tomar algún fruto de sus fatigas".

Luego refiere a la cláusula que está generando conflicto: plantar media cuadra de duraznos por año. Destaca que la susodicha no decía que debía hacerlo desde el primer año, "sino que al fin de los tres años había de dar plantados, a lo menos a razón de media cuadra por cada uno". Por ello, antes que nada invirtió y aseguró "los cercos con las zanjas plantando como ha hecho casi toda ella con tunas y pita". Incluso, el convento dio "su propio consentimiento (...) por el mal año respecto a la extraordinaria seca". Efectivamente, entre julio y diciembre de 1802 se produjo una sequía de gran magnitud, que generó un temor a la pérdida de cosechas y al desabastecimiento de carnes por la muerte, flacura y huida del ganado, a todo lo cual debía sumarse el ataque de langostas y plagas que afectaba a las hortalizas (Garavaglia, 1999, pp. 31-32). Esto repercutió en la variación de precios del trigo, cuya fanega se triplicó entre 1802 y 1803 (Johnson, 2013, pp. 246 y 262).

El orden de los argumentos no es azaroso. La falta del arrendatario está precedida por una descripción del desastroso estado de la campaña y por el consentimiento del padre guardián para que labore primero en el deslinde. Luego avanza sobre las falencias del contrato, ya que sólo tenía la acción de vigilar para que cumpliera las condiciones, mas no la "facultad de despojar". De modo que finaliza cambiando la carátula:

no se puede dejar de conocer la arbitrariedad, injusticia y exceso con que dicho Padre (...) pretende despojar (...) queriendo obligar a García a que la desalojase, y que le entregase la contrata para romperla habiendo este día dado orden (...) para que con los criados (...) por fuerza echándole el rancho al suelo.

Ante el embate, el síndico rechaza las "injustas y temerarias" acusaciones. Imputa a García que "se ha excedido también a recoger toda la leña (...) para quemar los ladrillos, en que ha sacado no poca utilidad". Esto le permite solicitar la cancelación del contrato, ya que "no puede olvidarse por un momento que el contrato 
desde su origen es insubsistente y tan esencialmente nulo", porque el convento, impedido por sus estatutos, no puede recibir utilidad o ganancia alguna.

En parte, resulta ser un arrendamiento que buscaba asegurar los derechos y los límites de la propiedad incrementando los frutales sin que hubiera una renta de por medio. La contrata tiene, tal vez, un halo de caridad, ya que permite al arrendatario asentarse para subsistir, sin que obtenga utilidad. En este sentido, para revocar el contrato niega la humildad del arrendatario al indicar que no tiene familia y que posee una sementera que produce una renta más que regular. Por ello, ataca al defensor de pobres por actuar con un arrendatario "acomodado".

El arrendatario recoge el argumento relativo a los estatutos y cuestiona la "mendicidad" de los franciscanos buscando socavar los derechos de propiedad de la corporación eclesiástica:

notará que ella no solamente versa en la referida comunidad de observantes con respecto a no poder contratar, labrar tierras, vender frutos, ni pactar en términos que aun remotamente pueda tener (...) rentas, sino que también esta incapacidad es absoluta e imposibilita a la comunidad de tener toda propiedad y dominio.

Por ello acusa de "malicia" al síndico, "que (...) conforme a las constituciones canónicas que reglan la materia, y a lo que diariamente se practica por dicho Síndico (...) es (...) de malicia el pretexto que se quiere tomar para argüir de nula mi contrata”. Evidentemente, la defensa fue exitosa porque la sentencia declaró "por subsistente el contrato de arrendamiento".

Es interesante destacar que hay una fortaleza de los arrendatarios de la Chacarita en el tiempo. Hacia 1836, cuando Rosas decidió vender dichas tierras, se halla la solicitud de propiedad de la viuda de Julián Tapia, antiguo "arrendatario eventual" que en 1783 pagaba cinco fanegas por año (Fradkin, 1997, p. 91). Argumentaba ser "viuda desvalida y pobre, con siete hijos", de los cuales algunos "han servido a la Santa Causa de la Federación”. Agregaba que la chacra fue poblada por los padres de su marido, quien auxilió con ganado a la "Restauración" (Del Pino, 1971, p. 39). En este sentido, Ciliberto destacó que la venta fue a arrendatarios que estaban en el lugar hacía 15 y hasta 50 años, y a labradores que prestaron "servicios al país" o que tuviesen "expresiones federales" (2013). Esta conjunción de argumentos políticos, de una economía moral según la diferencia entre disfrute y utilidad sumada a nociones ligadas a diversas tradiciones del derecho, sugiere la continuidad de un "haz de derechos" hacia 1836.

\subsection{Un conflicto en la Revolución: "que no todo es lo mismo"}

La pugna por los derechos a partir de un arrendamiento se destaca con mayor ahínco en el próximo expediente. En los meses febriles de mayo de 1810, en las quintas periurbanas que tenía el Colegio de San Carlos, se produjo un juicio por que tuvo sentencia de desalojo del arrendatario don Felipe Encina, que apeló ante la Real Audiencia ${ }^{8}$. El conflicto se inició luego del fallecimiento de don Félix Tadeo Encina, padre del arrendatario. Felipe dijo haber heredado dos parcelas arrendadas al Colegio. Una la labraba, y otra no. En esta última el administrador del colegio don Pedro Fernández colocó a don Felipe Flores y a don Francisco alias "el Gallego" Martínez.

Felipe Encina invocó al estatus de "pobre infeliz cargado de familia" para solicitar un defensor de pobres, y señaló que "el arrendatario que no lo es por tiempo no puede ser expelido del uso de la cosa arrendada pagando exactamente el arriendo". Al ser "arrendado sin término", no resulta forzoso pensar que quien resistía al desalojo no entendía que poseía una locatio -que no generaba presunción de propiedad-, sino que prácticamente refería a una enfiteusis feudal. En su defensa, traslucía una concepción de dominio dividido: el útil y el directo. Quien tenía el primero debía pagar a perpetuidad un canon que estaría reconociendo el derecho del segundo? .

Incluso juega con los argumentos al "prescindir por un momento de este derecho incontrastable que me concede la ley”, para atacar al presbítero en tanto autoridad: “¿Que titulo tiene en la Chacarita (...)? Hasta 
ahora nadie lo ha tenido por dueño ni por administrador, sino tan solamente por un mero mayordomo o encargado para recoger los arriendos". Por ello, exige la restitución del terreno y una reparación por "el lucro que se me priva". A esto, el administrador respondió que su padre trató con él en el arriendo por "los derechos de propiedad que representa". Luego, con elección precisa de las palabras, condenó la "ocupación que ha hecho de unos terrenos de labranza pertenecientes al mismo colegio... los ha ocupado pero no los posee, que todo no es lo mismo".

Aparentemente, el presbítero aguardaba los trámites de la testamentaria para tratar nuevamente el arriendo, pero advirtió que el hijo había traído a su familia desde Luján, y se tomó la "libertad de partir la segunda suerte en tres porciones", de las cuales dos subarrendamientos tenían vacas lecheras que destrozaban los montes. El contrapunto buscó ser resuelto extrajudicialmente, pero dijo haber recibido una agresiva respuesta que ponía en entredicho la propiedad: "que saliese del terreno, porque allí no había más dueño que él". Por este motivo colocó dos labradores que sirviesen para reconocer "por dueño al colegio". Por su parte, Felipe Encina amenazó con arar el lote, lo que demuestra que la puja por los derechos no se realizaba sólo en la administración de la justicia, sino también de facto.

Nuevamente, el artilugio jurídico era transformar el juicio de desalojo en uno por despojo, cuestión de la que da cuenta el presbítero: "Encina se quiere hacer fuerte en los terrenos... la posesión que alega, y el despojo que me imputa". Pero entonces sugiere que tal vez sea porque "ha oído decir que en los predios urbanos cuando se arriendan sin tiempo limitado se considera perpetua la locación”. En este sentido, plantea que "las reglas fundamentales" de la "locación rústica" eran diferentes a las urbanas, dado que en la primera se comprende la cosecha como el término legal aunque el "mutuo silencio de las partes se introduzca la tácita reconducción". Según el demandante, "dice una ley de partida; y hablando de la tácita reconducción de una heredad, establece, que se entiende arrendada por aquel año(...) Esta máxima ratificada más y más por las ultimas disposiciones de la nueva recopilación”. Así, las siete partidas como la recopilación castellana son invocadas. Pero el arrendatario también remitía a la "ley", sólo que sin detallar en este caso.

Continuemos con la argumentación del presbítero que alumbra la dinámica propietaria del período al referirse a la condición diferencial que había entre cada uno de los lotes: "supongamos (...) que los arrendamientos de heredades fuesen perpetuos, y no se fijasen a términos: supongamos también que la segunda suerte se la hubiese dado (...) con la misma perpetuidad, y que apareciese un documento que lo acreditase". En este caso estaba en juego la propiedad:

¿Se podría saber nunca el golpe, que se daba al dominio y propiedad particular? ¿Quién no ve que estos contratos degeneraban entonces y eran convertidos en verdaderas enfiteusis, que disimuladamente se defraudaba al propietario... y que una vez alquilada una cosa salía para siempre del poder de su dueño y se hacía en realidad enajenada?

Con nuevos argumentos, el presbítero hace hincapié en una "justicia natural” y en el principio de propiedad, que sería anterior a la costumbre y a la separación de las tierras de sementeras de las ganaderas, y servía para denunciar al arrendatario de perjudicial y dañino:

¿Cómo pudo Encina creer que le permitiese ningún Juez la permanencia de ganados trashumantes en tierras de labor y pan llevar, ni que le amparase en la [no se entiende una palabra] que está haciendo a todos los propietarios y vecinos? Un principio de justicia natural [no se entiende una palabra] anterior a toda ley, y a toda costumbre... clama contra estas violaciones de la propiedad.

Seguidamente, haber dividido la suerte inculta en tres porciones sería otro ataque a la propiedad: "un extraño sub-arrendatario contra la voluntad del dueño, es una disminución, es una verdadera ofensa de sus dueños".

Finalmente, el presbítero se opuso a que "Encina litigue en calidad de pobre", señalando una concepción de la pobreza como una condición en la que el individuo no tiene posibilidad de sostenerse por sus manos: "trabajando se remedian estos males". Sin embargo, el 22 de junio de 1810, el defensor de pobres Tomás 
Manuel Anchorena intercede en pos de "la restitución de una suerte de terreno, de que hallándose en posesión en clase de arrendador, le despojó de propia autoridad, colocando otros arrendatarios”.

La serie de testigos en el litigio fue presentada por el presbítero. Respondían un cuestionario formulado por su persona, donde aseveraban que estaba en entredicho los derechos de propiedad. Los dos nuevos arrendatarios afirmaban que el presbítero "le arrendó como dueño", y que fueron amenazados por Felipe Encina: "que aquel terreno no se lo tocase nadie porque era suyo". Asimismo, se preocuparon por negar la denuncia del demandando relativa a que no iba a quedar ni un criollo en las tierras del Colegio. Si entendemos que nos encontramos en un contexto revolucionario -a un mes del Cabildo Abierto del 22 de mayo de 1810-, la polarización y exacerbación en las formas políticas podrían estar jugando como condicionantes en la administración de justicia (Pérez, 2010). Finalmente, como testigos hay dos familiares del demandado su tío Felipe Flores, uno de los nuevos arrendatarios, y su hermano Juan Encina-, que declararon a favor del colegio. Aunque sea complejo comprobar, es posible plantear la existencia de un conflicto familiar que no podía solucionarse, y que aparece en la esfera de lo judicial.

La sentencia indicaba que los derechos estaban en manos del Real Colegio. Aclaraba la riesgosa interpretación del "arrendamiento sin término", afirmando que el demandado era un "mero inquilino". Por ello, en la apelación a la Real Audiencia, don Felipe cambió su estrategia y solicitó la restitución del lote ya no como poseedor, sino como inquilino, denunciando un despojo.

\subsection{La justicia letrada y el titulo de propiedad: los Almeyra y la renta}

En diciembre de 1821 la instancia judicial cambió abruptamente con la supresión de los Cabildos, que derivó en la instalación de una fugaz experiencia de justicia letrada de primera instancia en la campaña hasta fines de 1824. Anteriormente, la década revolucionaria reemplazó a la Real Audiencia por la Cámara de Apelaciones (Corva, 2014). En este sentido, el litigio que trabajamos es la apelación ante la Cámara iniciada en junio de 1824, que proviene de una sentencia del juez de paz del partido de Navarro y de la justicia letrada en 1821. Los autos eran por desalojo y pago de arrendamientos; la demanda fue iniciada por Juan Agustín Almeyra contra Gregorio Reynoso. El demandante era un letrado, con una familia con inversiones en tierras de frontera, inserto en las redes de poder local y en las más altas esferas del antiguo poder colonial, y con lazos comerciales extensivos al Brasil. En este conflicto se encuentra envuelto su hijo, Juan Pedro, que actúa coordinadamente en la causa ${ }^{10}$. Por su parte, el demandado tenía 40 años, no sabía firmar ni leer, tenía una familia con siete hijos, y los doce testigos hablaron de su buena conducta y honradez a pesar de reconocer que tomaba ganado ajeno. Se deduce que su economía mejoraba y, a causa de ello, fue demandado por arrendamiento. Su ascenso podría comprenderse en el ciclo de vida campesino (Mayo, 2004).

Según explica el demandante, don Gregorio llegó a las tierras como "arrimante" a solicitud de un arrendatario suyo, don Mariano Rocha, para que pueda sembrar "una o dos fanegas de trigo". Si bien "la costumbre del país" indicaba que debía pagar por el área sembrada, se le permitió establecerse sin renta. Sin embargo, observaron que sembró entre diez y veinte fanegas, "cuya cobranza era indisimulable", y que "con el cultivo de mis tierras se había puesto en prosperidad" ${ }^{11}$.

Almeyra tuvo una sentencia favorable del juez de paz que "ordenó el pago con arreglo a la costumbre", pero la primera instancia a cargo de Miguel de Villegas resolvió en septiembre de 1824 reducir "el cargo a menos de la cuarta parte, ordenando que Reynoso exista con su ganando por el presente año". Este primer indicio muestra un contexto en el que los jueces de paz comenzaban a tener influencia y ser parte de las redes locales de poder (Banzato y Valencia, 2005). De hecho, el juez de paz que hizo la primera sentencia fue Mariano Rocha ${ }^{12}$, y en 1828 nombrarían juez de paz de Navarro a Juan Pedro Almeyra.

En noviembre del mismo año, el juez de primera instancia del $2^{\circ}$ departamento de campaña explicó que don Gregorio Reynoso acudió a su persona, "expresando que hacia [uso] del recurso de apelación” porque 
"se le mandaba a pagar la... semilla, sin haber Don Juan Pedro Almeyra querido manifestar los títulos de propiedad y dominio". Por ello reclamó que lo hiciesen, cuestión que llevó adelante Juan Almeyra, y señaló que poseía las tierras desde 1795 recordando los peligros que pasó por ser frontera con el indio: "por esa consideración el Soberano Congreso declaró... legítima propiedad a los pobladores en mi especie para que se les librara un título no en gracia y merced, sino en registrada justicia”. Así, tras leerlos en voz alta, sentenció que el demandado debía pagar arriendos "correspondientes a dos años contados desde la fecha de la expedición de los títulos de propiedad", y agregó que debía devolver fanegas mal cobradas por tres años porque "le ha cobrado antes de ser dueño de los terrenos".

Estos criterios diferentes entre una familia, gran propietaria de tierras y estanciera, como los Almeyra y el juez de paz lego contra el letrado no se reduce sólo a cómo debía distribuirse la renta que generaba el labrador, sino también a dos concepciones contrarias a la propiedad. Los Almeyra exigían arriendo por 16 años, presentando como argumento la Real Instrucción de 1754, que reivindicaba que el mayor acto que otorgaba derechos de propiedad sobre la tierra era la denuncia y la consideración de "primer poblador". Por ello, el demandante recordaba que "en el año 1795 ordenó el Virrey a mi pedimento el lanzamiento de otros intrusos lo cual no es efecto de mera posesión sino un reconocimiento expreso de la propiedad que me da mi título". Pero para 1820 encontramos una creciente valoración de los papeles propiamente dichos de los "títulos". Así, la instancia de apelación letrada sentenció que sólo debía arriendo desde el 9 de marzo de 1822, desde la expedición del título.

Asimismo, el arrimado tenía conciencia de la relación que existía entre el juez de paz y los Almeyra, porque cuando exigió que se le mostraran los títulos, Juan Pedro Almeyra se "resistió por su carácter naturalmente caprichoso y dominante, y ni el Juez [de Paz] quiso ordenarle su exhibición (...) ya por la amistad con Almeyra y mucho más por el temor que le tiene". El problema no era casual ni individual. Si bien la forma judicial muestra sólo un demandado, la problemática era colectiva. Según Reynoso, "más de treinta pobladores habían sostenido con él un (...) dilatado pleito por muchos años acerca de la propiedad de ella".

Las concepciones del orden social son explicitadas por Juan Almeyra, quien buscaba crear lazos de subordinación y sujeción imbuidos de una pátina de paternalismo:

que siempre he mirado por mezquino y miserable el arrendamiento que se paga en trigos y dinero gloriándome de haber visto prosperar a muchos pobres con la gracia de no haberles cobrado un solo centavo (...) el mismo Reynoso es un testimonio irrefragable de esta equidad con que he mirado generalmente a cuantos se me han sometido.

La dependencia podía traducirse en el uso de una fuerza de trabajo, más aún con los arrimados, y en el acceso a una renta o en el reconocimiento de la propiedad. Pero en este caso, la situación no salió como deseaba. Almeyra tenía en claro que existía una lucha por los derechos de propiedad al explicitar que don Gregorio quería "disputarme el Señorío de aquellos terrenos", y que "los arrendamientos no son anexos exclusivamente a la propiedad porque son y pertenecen a la posesión”. Aquí es evidente que el arriendo pretendía restringir la independencia relativa de los paisanos y establecer un vínculo de deuda y dependencia con un "nuevo propietario" (Garavaglia, 1999, p. 341).

Más sintomático aún resulta que la misma situación se encuentre con los Almeyra en Luján. En otro litigio judicial aparece otra treintena de familias a las que pretendían someter con el mismo modus operandi. En 1812, Pascual Toro afirmaba que don Almeyra "pretende con un figurado derecho cual es el de denuncia, desalojarme de la población en que me hallo queriéndome estrechar auxiliado por el Comandante del Fortín" (Azcuy Ameghino, 2002, p. 184). Estas denuncias están en sintonía con las memorias de don Pedro Andrés García, quien da cuenta de los "nuevos" propietarios que querían desalojar a los labradores de la campaña (Gelman, 1997).

Pero Juan Agustín insiste en su embate para argumentar que la renta que le debía era de más años. Primero, define la relación con Gregorio como "clase de arrendero" más que "arrimado". Segundo, que la tierra no la tenía por "justicia", sino en "título de merced como a primer poblador de las tierras". Tercero, apela al artilugio 
jurídico de "injusticia notoria” para demandar la constitución de una comisión especial. Sin embargo, no se da lugar a la misma y la sentencia por desalojo se hace efectiva tras recoger la última cosecha. Prácticamente, un espejo de un mundo que estaba transformándose entre las costumbres y las nuevas concepciones de la propiedad.

\section{A modo de conclusión}

Nuestra investigación consistió en analizar a ras del suelo los discursos y prácticas de los derechos de propiedad a inicios del siglo XIX. Propusimos reflexionar en torno al ser "propietario" en la campaña de Buenos Aires, visualizando los argumentos con que los partícipes alegaban sus derechos a través de una fuente que ha sido estudiada para analizar las formas de la resistencia campesina (Fradkin, Robles, 2002), pero también para observar los cambios que se estaban produciendo en la relación entre las personas y las cosas, en particular la tierra.

En el antiguo régimen, Garriga considera que "el factor dinámico no era la ley [en sentido restringido] sino el conflicto, que impulsaba la construcción de las pretensiones o intereses fácticos como derechos... para producir enunciados normativos válidos" (2012, p. 97). Por ello adoptamos una metodología que contempla que el derecho en esta sociedad en transición no surgía sólo desde una órbita gubernamental, sino también a partir de las propias dinámicas sociales.

Así, iniciamos con una revisión crítica de la historiografía sobre la propiedad de la tierra y observamos las nuevas contribuciones de la historia agraria y de la historia crítica del derecho. Buscamos la alteridad de una época de transición que devenía de lo tradicional a lo moderno. Por nombrar un ejercicio de crítica conceptual, los riesgos del anacronismo pueden verse en el análisis de la distribución de la propiedad a partir de los censos que realizaban los vecinos como miembros de la notabilidad local, que no exigía documentación que convalidara los derechos sobre las tierras, dado que ya conocía por pública voz y fama quiénes eran los propietarios. Por ende, surgiría una tensión teórica y metodológica si concebimos que fueran "propietarios" sólo aquellos que tenían "títulos", pues, debería haber una comparación entre quienes figuran como "propietarios" en el censo y quienes lo hacen en los protocolos notariales. En su defecto, si la propiedad era un "haz de derechos" en el marco de la cultura jurisdiccional, es posible interpretar que la información proporcionada por los censistas era parcialmente certera, dado que al signar a unos como "propietarios" y a otros como "no propietarios", construían derechos para unos y los desconocían para otros. Por esto, creemos que la propiedad no estaba sólo acreditada por un "título", a pesar de que los tiempos estaban cambiando.

En la primera parte vimos la existencia de un creciente interés por la tierra, hecho sobre el que las demandas de desalojo funcionarían como evidencia. Algunas variables que lo explicarían son el crecimiento acelerado de la población, las diferentes concepciones de propiedad de los migrantes, la atlantización de la economía, la accesibilidad y volatilidad del metálico como del papel moneda, la demanda de trigo de la ciudad y el aumento de las exportaciones ganaderas -que ponían en tensión el uso de la tierra-, y la guerra y la reorganización institucional que caracterizó al período. La economía y la producción estaban en expansión. En este sentido, coincidimos con Gelman en que la lucha por la propiedad no obturó las condiciones para el crecimiento pero sí era relativa a la distribución de la renta agraria (2005).

En dicho contexto, los derechos de propiedad vinculados a la ocupación fueron puestos en duda frente a un proceso de homogenización y centralización legislativa que tendía hacia una compilación/codificación que fortalecía a una élite local (Anzoátegui, 2008). De hecho, la tensión entre concepciones estaba presente en las lecciones de derecho civil que dictaba Pedro Somellera en la Universidad de Buenos Aires: "dos posiciones convivían(...) desde los principios del derecho natural se consideraba el derecho del ocupante de tierras por encima de aquel que poseyera los títulos. Otros(...) planteaban el problema desde la falacia del argumento de la posesión como principio fundante de la propiedad" (Zeberio, 2009, p. 42). 
En el segundo tramo pudimos alumbrar estos matices. Cada argumento de las partes mostraba la existencia de un universo posible. Las exposiciones tenían como finalidad el desalojo del terreno o la resistencia, que implicaba mantener al menos la posesión, si es que la posesión era algo menor en términos jurídicos a la propiedad. En cierto modo, las estrategias para consolidar los derechos apelaban a diferentes órdenes normativos. Vimos demanda de tiempo hasta la próxima cosecha, la población en tierras realengas, el pago de arrendamientos a un propietario anterior, la manifestación de antigua posesión o condición de pobreza o de hacendado, el uso de los fueros personales y de las corporaciones -como el militar y el eclesiástico-, las redes de poder y las relaciones que funcionaban para reconocer derechos a otros, la demostración de animadversión de los demandantes ("malicia" o "actitudes temerarias") o criterios políticos como la revolución de 1810, las recopilaciones y los valores asociados a una "economía moral" basada en el "bien común" y la tensión que generaba entre "disfrute" y "utilidad", en la que la petición al ideal de la reposición de lo "justo" era una constante. La puja por los autos es un rasgo a destacar, al encontrarse que en dos casos se haya intentado cambiar la causa de "desalojo" en "despojo", lo que implicaba otro tratamiento procesal. Así, las partes construían una "cultura judicial" que se ponía en juego en el proceso, y que constituía una especie de "recetario" de acción promovido por la costumbre, los presupuestos económicos y morales, las leyes escritas del derecho local y real e, incluso, algunas ideas que podemos referir a la economía política.

Las diversas jerarquías entre las partes quedaban de manifiesto en la forma en la que se producían los conflictos. Por ello, una acción obligada para pensar la propiedad es la búsqueda de indicios que revelen la posición de los implicados. Así, no resulta casual que don Manuel García, prácticamente un empresario agrario, fuese quien resistió el desalojo.

Como decía Fradkin, las nuevas concepciones buscaron "despojar al derecho de propiedad de sus imperativos sociales y morales" (1999). Las Instrucciones a los mayordomos de estancias de Juan Manuel de Rosas expresaban este embate. Si proteger los bienes comunes y garantizar el abasto era una función primordial de los Cabildos en la consecución del "buen gobierno" y de la "quietud pública", la erradicación de los mismos cambiaría los parámetros de juego. De hecho, hacia mayo de 1810 surgieron "loas a las leyes positivas, de ataques al arbitrio judicial y de nuevos imperativos" (Candioti, 2011, p. 289), que anticipabanel cambio radical de 1821 que podría estar dado por el carácter letrado que asumía la justicia.

La nueva configuración del orden ponía en riesgo la autonomía campesina. Las concepciones liberales de la propiedad, asociadas al axioma del crecimiento, confrontaron con el arraigo de prácticas que eran parte de un marco normativo de antigua tradición. La búsqueda de estabilidad de un régimen político redundó en instituciones que, en parte, recayeron en élites locales que no necesariamente estaban en sintonía con las concepciones que motorizó la Circular a los jueces de paz de campaña de $1825^{13}$. Así, si bien se enarbolaba la prioridad de la sacralización de la propiedad, la reconstrucción de un orden político que tendiese a eliminar los rasgos facciosos y la formación una élite "homogénea" terminó predominando (Míguez, 2003; Gelman, 2016). Sin lugar a dudas, estas aseveracionesrequieren de una mayor exploración documental -comandancias de frontera, archivo del Cabildo, juzgados de paz, comisarías de campaña, protocolos notariales, Escribanía Mayor de Gobierno, tesis de jurisprudencia, manuales de doctrina jurídica o de práctica forense, entre otras-, como una mayor extensión temporal, pero consideramos que la vía adoptada es un camino por recorrer para capturar una noción de la propiedad que rompa el corsé del marco normativo.

\section{ReFERENCIAS}

Adelman, J. (1999). Republic of capital: Buenos Aires and the legal transformation of the Atlantic world. Stanford: Stanford University.

Amaral, S. (1998). The rise of capitalism on the pampas: the estancias of Buenos Aires, 1785-1870. Cambridge: Cambridge University.

Avellaneda, N. (1915) [1864]. Estudio sobre las leyes de tierras públicas. Buenos Aires: Librería de la Facultad. 
Assadourian, C. S. (1982). El sistema de la economía colonial. Mercado interior, regiones y espacio económico. Lima: Instituto de Estudios Peruanos.

Azcuy Ameghino, E. (2002). La otra historia. Economia, estado y sociedad en el Río de la Plata colonial. Buenos Aires: Imago Mundi.

Banzato, G. (2000). De ocupantes a propietarios, los conflictos entre vecinos de la frontera bonaerense. Chascomús y Ranchos, 1800-1840.Revista Quinto Sol, 4, 11-38

Banzato, G. (2001). La expansión territorial bonaerense, 1780-1880. Aportes de la historia local. Anuario del CEH, Año I,1, 85-93.

Banzato, G. y Valencia, M. (2005). Los jueces de paz y la tierra en la frontera bonaerense, 1820-1885. Anuario IEHS, 20, 211-237.

Barcos, M. F. (2013). Pueblos y ejidos de la campaña bonaerense: una historia sociojuridica de los derechos de propiedady la conformación de un partido: Mercedes, 1780-1870. Rosario: Prohistoria.

Barral, M. E., Fradkin, R., Luna, M., Peicoff, S., y Robles, N. (2007). La construcción del poder estatal en una sociedad rural en expansión: el acceso a la justicia civil en Buenos Aires (1800-1834). En R. Fradkin (comp.),Elpoder y la vara. Estudios sobre la justicia y la construcción del Estado en el Buenos Aires rural (1780-1830), 59-76. Buenos Aires: Prometeo.

Birocco, C. (1992). Arrendamientos rurales en la primera mitad del siglo XVIII. En G.Gresores, y C.Birocco, Arrendamientos, desalojos y subordinación campesina. Elementos para el análisis de la campaña bonaerense en el siglo XVIII, 45-109. Buenos Aires: Fernando García Cambeiro.

Bloch, M. (2002). La tierra y el campesino. Agricultura y vida rural en los siglos XVII y XVIII. Barcelona: Crítica.

Brown, J. (2001). North Meets South: Argentina y la Nueva Economía Institucional. Boletín del Instituto de Historia Argentina y Americana Dr. Emilio Ravignani, 3ª. Serie, nº 24, 127-141.

Campagne, F. (2005). Feudalismo tardio y revolución. Campesinado y transformaciones agrarias en Francia e Inglaterra (siglos XVI-XVIII). Buenos Aires: Prometeo.

Candioti, M. (2011). Los jueces de la revolución: pertenencia social, trayectorias políticas y saberes expertos de los encargados de hacer justicia. Buenos Aires, 1810-1830.En M.Alabart, M. A. Fernández y M.Pérez (eds.),Buenos Aires, una sociedad que se transforma: entre la colonia y la Revolución de Mayo, 287-324. Buenos Aires: Prometeo.

Canedo, M. (1993). Propiedades, propietarios y ocupantes. La tierra y la familia en la campaña de Buenos Aires. El Pago de los Arroyos, 1600-1750. Boletin del Instituto de Historia Argentina y Americana Dr. Emilio Ravignani, 7-30.

Cárcano, M. (1972). Evolución histórica del régimen de la tierra pública 1810 -1916. Buenos Aires: Eudeba.

Ciliberto, M. (2000). La agricultura a las puertas de la ciudad: arrendatarios, pequeños propietarios y grandes chacareros. Revista Quinto Sol, 4, 39-65.

Ciliberto, M. (2013). Derechos y prácticas de acceso, usufructo y propiedad en 'las tierras que fueron de los jesuitas'. Arrendatarios, propietarios y Estado en la campaña de Buenos Aires (primera mitad del siglo XIX).Ariadna Tucma Revista Latinoamericana, 2(7).

Clavero, B. (1974). La historia del Derecho ante la historia social. Historia, instituciones, documentos, 1, 239-262.

Congost, R. (2007). Tierras, leyes, historia. Estudios sobre la gran obra de la propiedad'. Barcelona: Crítica.

Congost, R., Gelman, J., y Santos, R. (eds.) (2017). Property Rights in Land. Issues in social, economic and global history.New York: Routledge.

Coni, E. (1927). La verdad sobre la enfiteusis de Rivadavia. Facultad de Agronomía y Veterinaria, Buenos Aires: Imprenta de la Universidad.

Corva, M. A. (2014). Constituir el gobierno, afianzar la justicia. El Poder Judicial de la provincia de Buenos Aires (1853-1881). Rosario: Prohistoria.

Del Pino, D. A. (1971). La chacarita de los Colegiales. Buenos Aires: GCBA.

Di Stefano, R. (1991). Un rincón de la campaña rioplatense colonial.Cuadernos del Instituto Ravignani, 1.

Echeverría, E. (1965). El Matadero. Buenos Aires: Kapelusz. 
Fradkin, R. (1992). Producción y arrendamiento en Buenos Aires del siglo XVIII: la hacienda de la Chacarita (1779-1784).Cuadernos de Historia Regional, 5(15), 67-98.

Fradkin, R. (1997). Reflexiones sobre historia agraria, regional y comparada: el arrendamiento de tierras de agricultura cerealera en la colonia tardía. Quinto Sol, 1, 41-74.

Fradkin, R. (1999). La experiencia de la justicia: estado, propietarios y arrendatarios en la campaña bonaerense. En AA.VV., La fuente judicial en la construcción de la memoria, 145-188. Mar del Plata: UNLP-SCJPBA.

Fradkin, R. (2000). El mundo rural colonial. En N. Goldman (comp.), Nueva Historia Argentina, Tomo 2, 241-284. Buenos Aires: Sudamericana.

Fradkin, R., y Robles, N. (2002). Juicios de desalojo y formas de resistencia subalterna en la campaña bonaerense durante la década de 1820.XVIII Jornadas de Historia Económica, Mendoza.

Garavaglia, J. C. (1983). Mercado interno y economía regional. México: Enlace Grijalbo.

Garavaglia, J. C. (1987). Economía, sociedad y regiones. Buenos Aires: Ed. de la Flor.

Garavaglia, J. C. (1999). Pastores y labradores de Buenos Aires. Buenos Aires: Ed. de la Flor.

Garavaglia, J. C. (2004). La propiedad de la tierra en la región pampeana bonaerense: algunos aspectos de su evolución histórica (1730 -1863). En R. Fradkin y J. C. Garavaglia (comp.), En busca de un tiempo perdido: la economía de Buenos Aires en el pais de la abundancia, 1750 -1865. Buenos Aires: Prometeo.

Garriga, C. (2004). Orden jurídico y poder político en el Antiguo Régimen. Istor, 16, 1-21.

Garriga, C. (2012). ¿La cuestión es saber quién manda? Historia política, historia del derecho y “punto de vista”. Revista PolHis, 10, 89-100.

Gelman, J. (1997). Un funcionario en busca del Estado. Pedro Andrés García y la cuestión agraria bonaerense. Buenos Aires: UNQ.

Gelman, J. (2000). Crisis y reconstrucción del orden en la campaña de Buenos Aires. Estado y sociedad en la primera mitad del siglo XIX. Boletin del Instituto de Historia Argentina y Americana "Dr. Emilio Ravignani", Tercera serie, $\mathrm{N}^{\circ} 21,7-31$.

Gelman, J. (2005). Derechos de propiedad, crecimiento económico y desigualdad en la región pampeana. Siglos XVIII y XIX. Historia Agraria, 37, 467-488.

Gelman, J. (2016). La construcción del Estado de Buenos Aires y los derechos de propiedad. Una aproximación cuantitativa desde los juicios de desalojo, 1810-1863. VEncontro rural RePort - XV Congreso de Historia Agraria de la SEHA, Lisboa.

Giberti, H. (1985). Historia económica de la ganadería argentina. Buenos Aires: Hyspamérica Ediciones Argentina.

Grossi, P. (1992). La propiedad y las propiedades. Madrid: Civitas.

Halperín Donghi, T. (1969). La expansión ganadera en la campaña de Buenos Aires (1810-1852). En T.Di Tella y T. Halperín Donghi (comp.), Los fragmentos del poder. De la oligarquía a la poliarquia argentina. Buenos Aires: Jorge Álvarez S.A.

Halperín Donghi, T. (1975). Una estancia en la campaña de Buenos Aires, Fontezuela, 1753 -1809. En E.Florescano (comp.), Haciendas, latifundios y plantaciones en América Latina, 447-463. México: Siglo XXI.

Herzog, T. (2015). Did European Law Turn American? Territory, Property and Rights in an Atlantic World. En T. Duve \& Pihlajamäki (eds.), New Horizons in Spanish Colonial Law. Contributions to Transnational Early Modern Legal History. Frankfurt: Max Planck Institut for European Legal History.

Infesta, M. E., y Valencia, M. (1987). Tierras, premios y donaciones. Buenos Aires: 1830-1860. Anuario IEHS, 2,177-213.

Infesta, M. E. (2003) [1991 tesis doctoral]. La pampa criolla: usufructo y apropiación privada de tierras públicas en Buenos Aires: 1820 -1850. Mar del Plata: EUDEM.

Irigoin, A. (1999). Introducción.Anuario IEHS, 14, 127-133.

Lanteri, S. (2011). Políticas oficiales y derechos de propiedad territorial indígena y campesina en la frontera sur de Buenos Aires durante el siglo XIX. XIII Congreso de Historia Agraria - Congreso Internacional de la SEHA, España. 
Marquiegui, D. N. (1990). Estancia y poderpolítico en un partido de la campaña bonaerense (Luján, 1756-1821). Buenos Aires: Biblios, Cuadernos Simón Rodríguez.

Mateo, J., y Moreno, J. L. (1997). El 'redescubrimiento de la demografía histórica en la historia económica y social. Anuario IEHS, 12, 35-56.

Mayo, C. (2004). Estancia y sociedad en la Pampa (1740-1820). Buenos Aires: Biblos.

Mayo, C., Mallo, S., y Barreneche, O. (1989). Plebe urbana y justicia colonial: las fuentes judiciales. Notas para su manejo metodológico. Estudios e Investigaciones, 1, 47-80.

Míguez, E. (2003). Guerra y orden social en los orígenes de la nación argentina, 1810-1880. Anuario IEHS, 18, 17-38.

Muñoz Arbeláez, S. (2011): 'Medir y amojonar'. La cartografía y la producción del espacio colonial en la provincia de Santa Marta, Nueva Granada, siglo XVIII. En J. C. Garavaglia y P. Gautreau (ed.), Mensurar la tierra, controlar el territorio. América Latina, siglos XVIII-XIX, 187-214. Rosario: Prohistoria

North, D. (1993). Instituciones, cambio institucional y desempeño económico. México: FCE.

Oddone, J. (1956). La burguesía terrateniente argentina. Buenos Aires: Ediciones Populares Argentina.

Palacio, J. M., y Candioti, M. (comp.) (2007). Justicia, politica y derechos en América Latina. Buenos Aires: Prometeo.

Pérez, M. (2010). La construcción del enemigo: el antiespañolismo en la literatura revolucionaria porteña (1810-1820). Anuario del Instituto de Historia Argentina, 10, 37-55.

Poczynok, C. (2016). Los derechos de propiedad en la campaña bonaerense (1800-1829)(Tesis de Licenciatura), FFyLUBA, Buenos Aires, Argentina.

Pugliese, M. R. (2005). Apuntamientos sobre la aplicación del Derecho indiano local en el Río de la Plata. Revista de Historia del derecho, 33, 219-295.

Rebagliati, L. (2009). La justicia y sus actores en tiempos de cambio: Los Defensores de pobres de Buenos Aires entre el periodo tardocolonialy la primera década revolucionaria (1776-1821)(Tesis de Licenciatura), FFyL-UBA, Buenos Aires, Argentina.

Reguera, A. (2009). La controversia de la propiedad de la tierra. Pensamiento, interpretación y realidad.En G.Banzato, y G.Blanco (comp.), La cuestión de la tierra pública en Argentina. A 90 años de la obra de Miguel Ángel Cárcano, 21-34. Rosario: Prohistoria.

Rosal, M. y Schmit, R. (2004). Las exportaciones pecuarias bonaerenses y el espacio mercantil rioplatense (1768-1854). En R. Fradkin, y J. C. Garavaglia (ed.), En busca de un tiempo perdido. La economía de Buenos Aires en el país de la abundancia. 1750-1865. Buenos Aires: Prometeo.

Tau Anzoátegui, V. (2000). Órdenes normativos y prácticas socio-jurídicas: La justicia. En Academia Nacional de la Historia, Nueva Historia de la Nación Argentina, Tomo 2, 283-316. Buenos Aires: Planeta.

Tau Anzoátegui, V. (2001). El poder de la costumbre. Estudios sobre el derecho consuetudinario en América Hispana hasta la emancipación. Buenos Aires: INHIDE.

Thompson, E. (1995). Costumbres en común. Barcelona: Crítica.

Vilar, P. (1983) [conferencia original en 1973]. Historia del derecho, historia 'total'. En Economía, Derecho, Historia, 106-140. Barcelona: Ariel.

Zeberio, B. (2009). El liberalismo y los derechos de propiedad en Argentina. Controversias jurídicas y proyectos políticos en la etapa codificadora. En G. Banzato y G. Blanco (comp.), La cuestión de la tierra pública en Argentina. A 90 años de la obra de Miguel Ángel Cárcano, 35-56. Rosario: Prohistoria.

Zeberio, B. (2005). Los hombres y las cosas. Cambios y continuidades en los derechos de propiedad (Argentina, siglo XIX). Revista Quinto Sol, 9, 151-183

Halperin Donghi, T. (2005). Guerra y finanzas en los orígenes del estado argentino: 1791-1850. Buenos Aires: Prometeo Libros 


\section{Notas}

1 Este artículo es resultado de una tesis de licenciatura (Poczynok, 2016)

2 AGN (s/f), Catálogo del Archivo de Tribunales: Civil, 1800-1863 (Vols., 1-3). Mecanografiado no publicado. Este catálogo se constituye cuando ingresan una tanda de expedientes judiciales en la sede actual del AGN tras el decreto $\mathrm{n}^{\circ} 5314$ del presidente de facto Pedro. E. Aramburu, que pretendía destruir estos documentos si nadie los reclamaba. Existen otras series que no utilizamos: Tribunales: Civil, expedientes sin letra [1710-1809] y Tribunales: Civil, alfabético [1608-1800].

3 Tales son los significantes como desalojo, tierras, terreno, arrendamiento, aparcería, alquileres, mensura, deslinde, posesión, propiedad, chacra, finca, quinta, estancia, hacienda, rancho, títulos y escritura. La forma en que se presenta en el catálogo es la siguiente: "Suárez Micaela con Median Bernardo sobre desalojo". En los casos en que en los autos se superponen las categorías - "Ibáñez Agustín con Erezcano José sobre deslinde de un terreno”-, fue consignado en el más específico.

4 En principio, agrupamos estos dos términos en una sola categoría dado que sólo con una lectura global profunda de dichos procesos podríamos aseverar la diferenciación analítica entre una y otra

5 AGN, TC, Leg. “A”, No1. Todas las citas pertenecen a este legajo

6 En noviembre de 1821, una Ley determinaba la prohibición absoluta de "cargar cuchillo, puñal, daga y toda arma corta”. En enero de 1830 se publicaba el "Decreto imponiendo penas á los individuos que hagan mal uso de las armas", donde se afirmaba que el motivo de dicha legislación era "aumentar las mejores garantías á la seguridad de los habitantes de esta Capital y su campaña” (ROPBA, varios tomos). En sus informes de campaña, el juez de paz de San Isidro declaraba en 1843 que velaba por la prohibición de portación (AGN, SX, 21-6-5). 0].

7 AGN, TC, Leg. “C”, $\mathrm{N}^{\circ} 4$. Todas las citas que refieran al expediente corresponden a este legajo.

8 AGN, TC, Leg. "E”, No 3. Todas las citas corresponden a este legajo

9 Según Fabián Campagne, la institución resultaba una ficción jurídica entre el dominium y la locatio. El dominium era "la propiedad privada absoluta sobre las cosas materiales, el derecho en virtud del cual un objeto se encuentra sometido a la voluntad y acción de una persona(...) lo que cotidianamente denominados propiedad, se describe técnicamente con el nombre de dominio", y la locatio era "la cesión temporaria del usufructo, del derecho de uso de una cosa" (2005, pp. 19-20)

10 Otro hijo de Juan Agustín, Mariano, también es poseedor de tierras en Navarro (Azcuy Ameghino, 2002, p. 182). Asimismo, hay varios juicios civiles de la familia en el fondo judicial.

11 AGN, TC, Leg. “A”, No 17. Todas las citas fueron extraídas de este legajo.

12 Capitán de Milicias, era hijo de don Francisco Rocha, antiguo regidor del Cabildo de Luján desde 1810 hasta 1815 (Marquiegui, 1990, p. 25)

13 La Circular planteaba la existencia de una "sociedad que se está organizando" en el "vacío de los campos y de la población”, donde los vecinos debían transformarse en portavoces de la civilización acompañados de los "funcionarios públicos”, los jueces de paz. Ahondaba en la persecución de los "perjudiciales” negando la condición de labradores a aquellos que poseían sólo una "choza”. Así, debían quedar en la campaña sólo aquellos en "calidad de propietarios" o de arrendamiento escrito. En Manual para los Jueces de Paz de Campaña, Imprenta de la Independencia, Buenos Aires, 1829. 